medecine/sciences $85 ; 1: 66-68$.

\title{
L'agent delta : biologie et pathobiologie
}

Le virus $D$ (ou agent $\delta$ ) est le dernier né des virus des hépatites. C'est un virus défectueux qui dépend étroitement du virus $B$ pour sa réplication. Cette caractéristique étonnante explique à la fois ses propriétés biologiques (détaillées dans cet article) et ses aspects épidémiologiques.

\section{Christian Bréchot}

\section{Chef de clinique-assistant.}

\section{REFERENCES}

1. Rizzetto M, Canese MG, Arico S et al. Immunofluorescence detection of new antigen-antibody system delta/anti-delta associated to hepatitis $B$ virus in liver and serum of $\mathrm{HBs}$ Ag carriers. Gut 1977; 18 : 997-1003.

2. Rizzetto M. the del agent. Hepatology 1983 ; $3: 729-37$.

3. Rizzetto M, Hoyer B, Canese MG, Shih JWK, Purcell B, Gerin JL. Delta antigen : the association of delta antigen with hepatitis $B$ surface antigen and ribonucleic acid in the serum of delta infected chimpanzees. Proc Natl Acad Sci USA 1980; 77 : 6124-8.

4. Rizzetto M, Shih JWK, Gerin JL. The hepatitis B virus-associated delta antigen $(\delta)$ : isolation from liver, development of solid phase radioimmunoassays for delta and antidelta and partial characterization of delta. 7 Immunol 1980; 1 $25:$ 31 8-24

\section{ADRESSE}

Unité de Recombinaison et Expression Génétique, (Inserm U 63, Cnrs LA 271), Institut Pasteur, 28, rue du Docteur-Roux, 75015 Paris.

Unité d'Hépatologie. Hôpital Laënnec, 42, rue de 'antigène delta $(\delta)$ a été identifié pour la première fois par Rizzetto en 1977 à partir d'une analyse en immunofluorescence de biopsies de foies de porteurs chroniques du virus de l'hépatite $B$ (VHB) en Italie [I, 2]; il fut en effet démontré qu'il existait dans le noyau des hépatocytes de certains malades infectés par le VHB un antigène distinct des antigènes de surface (Ag HBs) et de capside (Ag HBc) du virus B. Des études réalisées chez le chimpanzé puis chez l'homme ont par la suite permis de montrer que l'infection $\delta$, si elle nécessite une infection préalable ou associée par le VHB, est cependant due à un virus différent du virus $B$.

\section{Structure moléculaire du virus $D$}

La particule $\delta$ a été identifiée à partir du sang de chimpanzés et d'humains infectés $[3,4]$ : le matériel antigénique n'est détecté après ultra centrifugation que si des détergents sont utilisés, ce qui indique qu'il est localisé à l'intérieur de particules,
Ces particules mesurent 35 à $37 \mathrm{~nm}$ et portent les déterminants de l'antigène HBs (fig. 1). Leur densité $\left(\mathrm{I}, 25 \mathrm{~g} / \mathrm{cm}^{3}\right.$ dans un gradient de chlorure de césium) et leur taille sont intermédiaires entre celles des particules VHB complètes (particules de Dane de $42 \mathrm{~nm}$ ) et celles des particules VHB défectives (particules de $22 \mathrm{~nm}$ portant seulement l'Ag HBs). L'antigène $\delta$ a été purifié à partir du foie, puis du sérum humain : il s'agit d'une protéine de $6,8 \cdot 10^{4}$ daltons.

Il a été possible d'isoler une molécule d'ARN à partir des particules associées à l'antigène $\delta$. Après dénaturation au glyoxal, la taille de l'ARN a été estimée à I,75 kilobases. Cette taille est donc supérieure à celle des viroïdes et nettement plus petite que celle des virus à ARN connus. Cet ARN est différent des ARN ribosomiaux (I8 $\mathrm{S}$ et $28 \mathrm{~S}$ ) qui auraient pu être libérés dans le sérum avec l'antigène $\delta$ à partir d'hépatocytes nécrosés. Les différences de migration de l'ARN suivant les conditions de dénaturation utilisées suggèrent l'existence d'appariemments internes dans la molécule, qui aurait pro- 


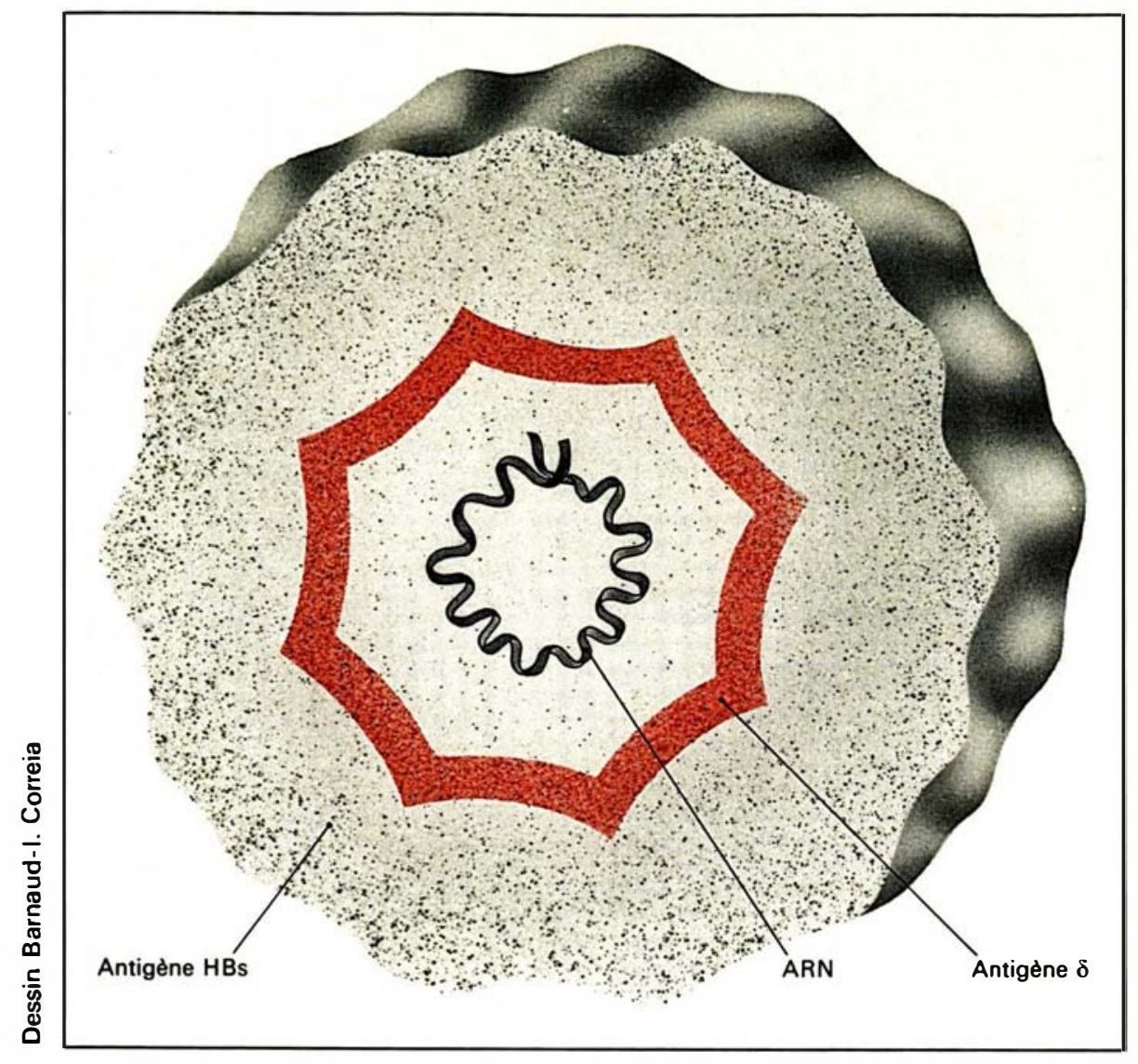

Figure 1. Représentation schématique de l'agent $\delta$ (ou virus de l'hépatite D). L'ARN est au centre de la particule, ainsi que l'antigène $\delta$. L'enveloppe est consituée par l'Ag HBs. La taille de la particule est de 35 à $37 \mathrm{~nm}$.

bablement une structure linéaire avec une extrémité $3^{\prime}$ libre $[3,5,6]$. Il n'a pas été détecté d'activité reverse transcriptase associée au virus D. De plus, l'ARN n'a pas de séquences "Poly $A$ " à son extrémité $3^{\prime} \mathrm{OH}$, ce qui le fait comparer à un virus à $A R N$ à brin négatif ou à un ARN d'histone ou de plantes. L'ARN a la possibilité de coder pour une protéine de $6,2.10^{4}$ daltons qui pourrait donc être l'antigène $\delta$ bien que cela ne soit pas actuellement prouvé. $\mathrm{m} / \mathrm{s}$ avril 85 que et de le cloner dans un plasmide [6]. Cela permettra l'analyse de la séquence en nucléotides du génome viral. Cependant actuel- lement, la séquence d'ADN complémentaire clonée ne correspond qu'à une petite région de l'ARN [6].

L'ARN du virus D n'a pas d'homologie détectable avec l'ADN du virus de l'hépatite $B$ : cela a été montré par l'absence d'hybridation entre, d'une part l'ARN du virus D et une "sonde " faite d'ADN du virus $B$ marqué au phosphore 32 , et d'autre part l'ADN du virus $B$ et un ADN complémentaire de l'ARN du virus $\mathrm{D}$ marqué également au phosphore 32 .

\section{Agent delta et}

Bien que la structure du génome viral et la biologie de ce virus soient encore très mal connus, il semble que le virus $\mathrm{D}$ soit un virus défectueux nécessitant la présence du virus $B$ et l'expression de l'antigène HBs pour sa multiplication [2]. Cela est suggéré par deux types d'observations. En premier lieu, l'étude de la structure de la particule $\delta$ indique clairement la nécessité de la présence de l'antigène HBs pour fournir une enveloppe à ce virus [3]. En second lieu, l'analyse de l'épidémiologie des infections par ce virus chez l'homme a montré qu'elles étaient toujours associées à une infection (aiguë ou chronique) par le virus B (Voir l'article de J. Bernuau dans ce même numéro). Un chimpanzé ne peut être infecté par le virus $D$ que s'il est porteur du virus $B$ [7]. L'infection $\delta$ peut être obtenue soit par injection simultanée des deux virus, soit par surinfection d'un chimpanzé porteur chronique du virus B. Dans ce deuxième cas, la synthèse intrahépatique de l'antigène $\delta$ et son excrétion dans le sérum sont très importantes et des lésions d'hépatite aiguë apparaissent, faisant discuter une action directement cytotoxique du virus $\mathrm{D}$ [7]. Parallèlement, l'infection $\delta$ diminue la multiplication du virus $B$, comme le montre la disparition de l'antigène $\mathrm{HBe}$, de l'ADN du VHB sérique et de l'activité $\mathrm{ADN}$-polymérase virale séri- 
que. De plus les études réalisées chez ces animaux ont montré le caractère extrêmement infectieux du virus $D$. Le virus $D$ a pu être également transmis à certaines espèces de marmottes infectées par un virus de structure très semblable à celle du VHB. Là encore, l'infection $\delta$ n'est obtenue que si l'antigène de surface du virus de la marmotte est présent dans le sérum. L'agent $\delta$ est alors présent dans des particules de 35 à 37 nanomètres portant les déterminants de cet antigène de surface $[2,8]$.

\section{Détection de I'antigène delta}

L'antigène $\delta$ n'est détecté dans le sérum que très transitoirement, l'anticorps anti- $\delta$ apparaissant précocément; dans le foie l'antigène $\delta$ est détecté essentiellement dans le noyau des hépatocytes et parfois dans le cytoplasme [1, 2]. Des études en microscopie électronique et immunoélectromicroscopie n'ont pas permis d'individualiser des particules intranucléaires spécifiques $\mathrm{du} \delta$. Les seules anomalies observées dans le cytoplasme d'hépatocytes de chimpanzés infectés par le virus $\mathrm{D}$ sont des structures tubulaires semblables à celles observées au cours d'infections par des virus non A-non B [2].

Le diagnostic des infections $\delta$ a jusqu'à présent été fondé sur la détection de l'antigène $\delta$ et de l'anti- $\delta$ par des tests radioimmunologiques utilisant un antigène $\delta$ purifié à partir du foie [4] ou du sérum. Le clonage d'un ADN complémentaire à l'ARN du virus $D$ (ADNc) a récemment permis d'utiliser cet ADN comme une sonde après marquage au phosphore 32 et, après hybridation, de détecter l'ARN viral dans le sérum et le foie [9]. Cependant, cet ADNc ne correspond actuellement, pour des raisons techniques mal comprises, qu'à une petite région de l'ARN du virus $D$, ce qui limite l'intérêt diagnostique de cette sonde. On peut néanmoins espérer, dans les prochaines années, disposer de sondes complètes qui permettront d'identifier directement les particules $\delta$ contenant l'ARN et de rechercher la possibilité de sous-types différents du $\delta$

\section{Summary}

The delta agent has been identified by Rizzetto in the liver and serum of hepatitis $B$ virus (HBV) carriers; it consists in a defective RNA virus whose envelope bears the antigenic determinant of the HBV surface antigen. The delta antigen and a small RNA molecule are present in the inner part of this particle. Experiments conducted in chimpanzees and clinical observations in man suggest that the delta agent is a defective virus whose multiplication is only possible in hepatocytes infected by the HBV. In addition the delta agent seems to be responsible of direct cytotoxic effects; this would explain the worsening of the course of liver disease in HBV carriers after superinfection with the delta agent. que, (Inserm U 63, Cnrs LA 27I), Institut Pasteur, 28, rue du Docteur-Roux, 75015 Paris.

Unité d'Hépatologie. Hôpital Laënnec, 42, rue de Sèvres, 75007 Paris. 